\title{
Hematological profiles of football players according to playing positions in Tigray region, Ethiopia
}

\author{
Mulugeta Worku ${ }^{1} \odot$ Soumitra Mandal ${ }^{1}, \odot$ Saravanan Muthupandian $^{2}$, \\ - Leyekun Tadesse ${ }^{1}$
}

${ }^{1}$ Department of Sports Science, Mekelle University, Tigray, Ethiopia. ${ }^{2}$ Department of Medical Microbiology and Immunology, Mekelle University, Tigray, Ethiopia.

\begin{abstract}
The Objectives study was to compare hematological profiles of different playing position football players in the Tigray region, Ethiopia. The study was conducted in northern parts of Ethiopia, had played in the Ethiopian premier league, super league, and National league competition programs. Descriptive Cross-sectional design and quantitative research methods were employed to compare hematological variables of different position soccer players. To get appropriate data voluntary health soccer players were selected through purposive sampling techniques. Goalkeepers (GK, 15), Defenders (DF, 27), Midfielders (MF, 36) and Strikers (ST, 23) based on player's position 101 players were selected from a total of 200 Tigray regions. Data were analyzed by one-way analysis of variance (ANOVA) to conclude the differences between GK, DF, MF, and ST soccer players and Post Hoc test (LSD) applied at $\mathrm{p}<.05$. No significant difference was found between playing positions in $\mathrm{WBC}, \mathrm{RBC}, \mathrm{HGB}$, HCT, MCV, MCH, MCHC, PLT, LYM\%, NEUT\%, LYM\#, NEUT\#, RDW, PDW, MPV, and PCT ( $p>$.05). Coaches and Medicals might take into consideration positional differences, age, BMI, and training status of players during testing hematological profiles.
\end{abstract}

Keywords. Complete blood count, football, hematology, playing position.

\section{Introduction}

Soccer is the most attractive sport in the world and during 90 mints of competitions session, male soccer players have a higher $\mathrm{VO}_{2} \max$ and maximum heart rate as compared with that of female soccer players. Evaluating the training load and intensities, heart rate and time-motion analysis is important to four players and coaches (Jastrzebski et al., 2016). Soccer sport needs high- intensity training and hematological and biochemical parameters are helpful to predict the physical performance. Physiological variables are important for doctors and coaches to follow up (Baralić et al., 2014). $\mathrm{VO}_{2} \max$ and hemoglobin concentration significantly increased football players who made competition as compared with that of low altitude region soccer players. Researchers concluded that further studies should be performed (Cossio-Bolaños et al., 2015). Consistence hematological parameters are key indicators of maximum sports performances. The Objectives of the study were to test seasonal effects such as before, during and after match training on the hematological status of soccer players. Seventeen professional European soccer players participated in the study. The results of the study showed that there was no correlation between White Blood cells, Neutrophils, training sessions, and competition. As the researcher concluded that mean corpuscular hemoglobin and mean corpuscular volume values during competition time strongly associated with session and training of professional soccer players. Regular blood testing was important to the rotation of soccer players (Bragazzi et al., 2018).

The relationship of hematological parameters with specific fitness performances of top soccer players' study showed that hemoglobin mass was positively correlated with $\mathrm{VO}_{2}$ max. But there was a negative correlation with a repeated-sprint ability (Boucherie et al., 2015). Hematological changes and prevalence of anima of different position Brazilian soccer players. Thirty-eight professional soccer players were participated and tested $\mathrm{VO}_{2}$ max, 
anthropometric and hematological variables. The results of the study showed that there were no significant differences between RBC, HCT, and HGB of different position soccer players and there was no anemia in soccer players. The researchers has concluded that hematology of soccer players influenced by age, sex, training altitude, nutrition and ethnicity (Santi Maria et al., 2013).

Comparative studies on hemoglobin concentration of soccer players at different altitudes. Forty-two soccer players were from sea level and a moderate altitude region participated in the study. The results of the study showed that there were significant differences in moderate altitude soccer players in hemoglobin concentration and $\mathrm{VO}_{2}$ max as compared with seal level players. The researcher concluded that soccer players better perform at moderate altitudes because of hypoxia increase the volume of red blood cell and increase $\mathrm{O}_{2}$ carrying capacity (Cossio-Bolaños et al., 2015).

Football competition is exposed by hematological, physical and psychological stress. Consuming a balanced diet can increase iron and hemoglobin contents in the blood, which helps to develop the performance of soccer players (Sporis et al., 2016). The preparation period increases the soccer player's hematological parameters because of aerobic capacity improved. Eventually, researchers recommended that to achieve the best performances of players, coaches should measure the hematology of players (Anagnostakos et al., 2015). Significant differences found on physiological and physical variables in different positions of football players. A coach can use the results of physiological and physical fitness tests to plan and design the training programs that develop the performance of soccer players (Sporis et al., 2009). Modern period hematological parameters are useful to predict the performance of players. But, a slight emphasis has been given for the evaluation of the hematology of soccer players (Santi Maria et al., 2013). Sport hematology is subdisciplines of sports medicine developed in the previous 20 years. Sport hematology focused on hemoglobin concentration that transports $\mathrm{O}_{2}$ and blood doping, especially in Olympic game competitions, some athletes and cyclists suffered from it. The sport hematology study also concerned about the relationship between sickle cell trait and unexpected death (Shaskey \& Green, 2000).

Soccer is played by all ages and levels of society. Soccer performance depends on the physiology, hematological and psychological parameters of players. Therefore, these descriptive-analytical studies have significance for players, coaches and researchers (Stølen et al., 2005). Hematological parameters are helpful to measure the effect of exercise training on performance and health condition of soccer players. Ethiopia had participated in the African cup of the nation, but not in the world cup. Tigray regional clubs are Suhul Shire F.C, Tigray Wuha Sera F.C, Dadabit F.C, Mekelle 70 Enderta F.C., and Walwalo Adigrte University football clubs are newly emerging and participated in the Ethiopian premier league, super league, and national first league starting from the 2010 EC. But Dedabit football clubs participated in the Ethiopian premier league for a long time. There is no enough scientific evidence about hematological parameters of football players specific to this region. The recent study aimed to compare the hematological parameters of football players according to their playing positions in Tigray region.

\section{Methods}

This research study paper does not affect the morals and health of soccer players. Soccer players participated in this research study and venous blood collected by signing the consent form. The study was conducted based on national and international scientific guidelines code of ethics (Declaration of Helsinki) approved Number of ERC-1376/2019 approved by Mekelle University, health research ethics review committee (HRERC).

\section{Study Area}

The research study was conducted in northern parts of Ethiopia, Tigray region Mekelle, Adigrate, and shire town representing clubs who had played 
in the Ethiopian premier league, super league and National league competition programs.

\section{Research Design}

To conduct study descriptive Cross-sectional design and quantitative research methods were employed to test and compare hematological variables of different position soccer players because data were taken from players at one time during a preparatory season.

\section{Sampling Technique}

To get adequate data voluntary soccer players were selected through purposive sampling techniques. Goalkeepers (15), Defenders (27), Midfielders (36) and Strikers (23) football players based on player's position 101 players were selected from a total 200 Tigray region, Ethiopia. Soccer players were in good health conditions and injured players not included in the study. All players were registered to play in the Ethiopian premier league, super league, and National league competition format.

\section{Blood Sample Collection}

The blood samples were collected during the precompetition season morning at the resisting position. The research participant sits comfortably in a chair. The participant's arm was placed in a downwards position supported on the armrest. A tourniquet was applied to the upper arm on the chosen side $7-10 \mathrm{~cm}$ above the intended venipuncture site. The tourniquet was moderately tight, with the radial pulse at wrist still palpable. The tourniquet was in place no longer than one and a half minutes. With the Vacationer barrel held between the thumb and index finger and needles along the line of the vein at an approximately 15-30 degree angle to the skin, the lab technician ensures the bevel of the needle was in the upwards position and inserts the needle through the skin into the median cubital vein. Upon completion of the blood draw, the Tourniquet was removed and the needle is withdrawn from the vein quickly and cotton pressed on the site of venous puncture. Then, a 5- $\mathrm{ml}$ venous blood sample was drawn from football players transferred to EDTA (Ethylenediaminetetraacetic acid) Tube and blood mixed to prevent clotting. The entire collected blood sample puts into a transport rack and placed inside a plastic bag. Then after transport to Mekelle University Ayder specialized hospital hematology laboratory to determine CBC (complete blood count). The collected blood in the EDTA tubes was transferred to a centrifuge sigma machine to separate plasma and blood. Also centrifuged (2000 $\mathrm{RPM})$ at 4 degrees centigrade for 20 minutes and then $\mathrm{CBC}$ measured Hematology analyzer (Sysmex-300) by hospital laboratory technicians.

\section{Statistical Analysis}

The data obtained from the football players' laboratory test was first collected, organized, tabulated, and coded in SPSS version 21. Descriptive statistics mean and standard deviation are used to analyze basic information and distribution of scores. The data collected through lab-tested and field -tests are summarized and analyzed quantitatively. Hematological profiles of soccer players' data were analyzed by one-way analysis of variance (ANOVA) to determine differences among Goalkeepers, defenders, midfielders, and strikers. Multiple -compassion Post Hoc test (LSD) was applied as the significant alpha value of $(\mathrm{p}<.05)$.

\section{Results}

Table 1 shows football players' demographic data. All players were having no significant difference in age and BMI ( $p>.05)$. There was also significance mean the difference between height and weight of different playing position football players $(\mathrm{p}<.05)$.

As Table 2 was shown, results indicated that there was no significant mean differences between Goalkeepers, Defenders, Midfielders and Strikers in in WBC, RBC, HGB, HCT, MCV, MCH, MCHC, PLT, LYM\%, NEUT\%, LYM\#, NEUT\#, RDW, PDW, $\mathrm{MPV}$, and PCT of selected Tigray region football players $(p>.05)$. 


\section{Table 1}

Demographic and Anthropometric characteristics of different playing position in football players (Mean \pm SD).

\begin{tabular}{lccccc}
\hline Variables & GK & DF & MF & SK & All Positions \\
\hline Age (years) & $24.20 \pm 3.32$ & $24.67 \pm 3.19$ & $23.69 \pm 3.64$ & $23.83 \pm 3.70$ & $24.06 \pm 3.46$ \\
Height $(\mathrm{M})$ & $1.80 \pm .08$ & $1.75 \pm .06$ & $1.75 \pm .07$ & $1.72 \pm .06$ & $1.75 \pm .07$ \\
Weight $(\mathrm{kg})$ & $75.87 \pm 5.81$ & $68.07 \pm 6.37$ & $69.42 \pm 8.30$ & $66.52 \pm 7.19$ & $69.36 \pm 7.71$ \\
BMI $\left(\mathrm{kg} / \mathrm{m}^{2}\right)$ & $23.42 \pm 2.28$ & $22.33 \pm 1.67$ & $22.66 \pm 2.29$ & $22.55 \pm 1.82$ & $22.66 \pm 2.03$ \\
\hline
\end{tabular}

GK: Goal Keeper, DF: Defender, MF: Midfielder, SK: Striker, BMI: Body Mass Index

\section{Table 2}

Hematological characteristics of different playing positions in football players $(\mathrm{M} \pm \mathrm{SD})$.

\begin{tabular}{|c|c|c|c|c|c|c|c|}
\hline Variables & GK & DF & MF & SK & All Positions & $\mathrm{F}$ & $\mathrm{p}$ \\
\hline WBC $\left(\times 10^{\wedge} 3 / \mu \mathrm{L}\right)$ & $5.61 \pm 1.56$ & $5.86 \pm 1.97$ & $6.34 \pm 1.94$ & $6.38 \pm 2.12$ & $6.11 \pm 1.93$ & .807 & .493 \\
\hline $\mathrm{RBC}\left(\times 10^{\wedge} 6 / \mu \mathrm{L}\right)$ & $5.49 \pm .42$ & $5.37 \pm .43$ & $5.37 \pm .43$ & $5.24 \pm .46$ & $5.36 \pm .43$ & 1.003 & .395 \\
\hline $\operatorname{HGB}(\mathrm{g} / \mathrm{dl})$ & $16.53 \pm .95$ & $16.07 \pm .96$ & $17.02 \pm 5.90$ & $16.01 \pm .67$ & $16.46 \pm 3.58$ & .512 & .675 \\
\hline HCT (\%) & $48.20 \pm 3.46$ & $47.01 \pm 2.94$ & $48.60 \pm 6.97$ & $46.38 \pm 3.25$ & $47.61 \pm 4.91$ & 1.184 & .320 \\
\hline $\operatorname{MCV}(\mathrm{fl})$ & $88.01 \pm 3.34$ & $87.71 \pm 4.41$ & $88.95 \pm 3.23$ & $88.72 \pm 4.51$ & $88.43 \pm 3.88$ & .621 & .603 \\
\hline $\mathrm{MCH}(\mathrm{pg})$ & $30.27 \pm 2.47$ & $30.05 \pm 2.69$ & $30.03 \pm 2.16$ & $30.74 \pm 2.80$ & $30.23 \pm 2.48$ & .442 & .724 \\
\hline MCHC (g/dl) & $34.41 \pm 2.49$ & $34.25 \pm 2.02$ & $33.76 \pm 1.91$ & $34.63 \pm 2.32$ & $34.19 \pm 2.12$ & .883 & .453 \\
\hline $\operatorname{PLT}\left(x 10^{\wedge} 3 / \mu \mathrm{L}\right)$ & $240.07 \pm 92.0$ & $235.19 \pm 65.64$ & $238.25 \pm 51.17$ & $230.17 \pm 39.53$ & $235.86 \pm 59.81$ & .111 & .953 \\
\hline Lym \% (\%) & $39.07 \pm 10.46$ & $39.05 \pm 9.61$ & $34.81 \pm 9.26$ & $36.05 \pm 9.79$ & $36.86 \pm 9.70$ & 1.317 & .273 \\
\hline NEUT \% (\%) & $49.43 \pm 16.00$ & $50.31 \pm 11.93$ & $52.49 \pm 11.82$ & $52.44 \pm 11.54$ & $51.44 \pm 12.35$ & .339 & .797 \\
\hline LYM\# $\left(10^{\wedge} 3 / \mu \mathrm{L}\right)$ & $2.07 \pm .41$ & $2.14 \pm .48$ & $2.08 \pm .44$ & $2.15 \pm .49$ & $2.11 \pm .45$ & .201 & .895 \\
\hline NEUT\# $\left(10^{\wedge} 3 / \mu \mathrm{L}\right)$ & $2.97 \pm 1.51$ & $3.12 \pm 1.51$ & $3.47 \pm 1.61$ & $3.52 \pm 1.97$ & $3.3109 \pm 1.65$ & .561 & .642 \\
\hline RDW (\%) & $13.15 \pm 1.23$ & $13.10 \pm 1.18$ & $13.07 \pm 1.07$ & $12.88 \pm .88$ & $13.05 \pm 1.08$ & .258 & .856 \\
\hline PDW (fl) & $14.15 \pm 2.66$ & $14.35 \pm 2.70$ & $13.59 \pm 2.39$ & $14.83 \pm 3.39$ & $14.16 \pm 2.76$ & .997 & .398 \\
\hline MPV (fl) & $9.87 \pm 1.07$ & $10.37 \pm 1.58$ & $10.03 \pm .90$ & $10.39 \pm 1.05$ & $10.18 \pm 1.17$ & 1.035 & .381 \\
\hline РCТ (\%) & $0.25 \pm .08$ & $0.24 \pm .05$ & $0.25 \pm .04$ & $0.24 \pm .04$ & $0.24 \pm .05$ & .225 & .879 \\
\hline
\end{tabular}

GK: Goal Keeper, DF: Defender, MF: Midfielder, SK: Striker, WBC: White Blood Cell, RBC: Red Blood Cell, HGB: Hemoglobin, HCT: Hematocrit, MCV: Mean Corpuscular Volume, MCH: Mean Corpuscular Hemoglobin, MCHC: Mean Corpuscular Hemoglobin Concentration, PLT: Platelet, Lym\%: Lymphocyte Percentage, NEUT\%: Neutrophil Percentage, LYM\#: Lymphocyte Count, NEUT\#: Neutrophil Count, RDW: Red Cell Distribution Width, PDW: Platelet Distribution Width, MPV: Mean Platelet Volume, PCT: Platelet Crete.

\section{Discussion}

Soccer sport needs physical, physiological, technical and psychological abilities of soccer players. Players should have good body composition and significant hematological changes that affect the health status of players (Bussollaro et al., 2018). The study aimed to evaluate body composition and hematological change of soccer players according to their playing positions. The results of the study showed that there was no significant changes in WBC, RBC, HGB, HCT, $\mathrm{MCV}, \mathrm{MCH}, \mathrm{MCHC}$, PLT, LYM\%, NEUT\%, LYM\#, NEUT\#, RDW, PDW, MPV, and PCT. Hematological variables in football players were similar according to their playing positions. A study, which described the hematological and biochemical variables of soccer players, concluded that there were small significant changes in hematological parameters, but no change in body 
composition of football players (Anđelković et al., 2015). A total of 19 players participated in the study. The results of the study showed that there was a significant decrease in hemoglobin, hematocrit Lymphocyte count, and muscle enzyme plasma activity. No change in erythrocyte count and iron level. Also, there was a significant increase in leukocyte and neutrophil counts levels of football players. Concluded that sports doctors and coaches better to test and follow up regularly to identify the health status and performances of soccer players.

Except for RBC (Red blood cell), there are no significant differences in WBC (white blood cell), LYm (lymphocyte), PLT (Platelet), HGB (hemoglobin), and HCT (hematocrit) because of age, filed conditions and nutrition. Hence, when evaluating the hematological test physician should take into consideration the age and training conditions of soccer players (Joksimović et al., 2009). Long term regular exercises significantly change biochemical and hematological parameters of players. Soccer players within 45 days of training hemoglobin, hematocrit and MCV significantly reduced, but no change occurs on red blood cell volume (Baralić, I. and et al., 2014). Hematological variables are helpful for diagnosis, control, and prevention of the health conditions of players. After one game competition WBC, RBC, HGB, HCT, PLT \& PCT increased, but there is no significant change in MVC, MHC, MCHC, RDW, and MPV hematological variables at $\mathrm{p}<.01$ (Younesian et al., 2004).

Although midfields had higher Hematocrit (HCT) $(\mathrm{M}=48.603)$ than goalkeepers $(\mathrm{M}=48.2)$, defenders $(\mathrm{M}=47.01)$ and Strikers $(\mathrm{M}=46.38)$. Strikers had a higher white blood cell (WBC) $(M=6.38)$ than Midfielders $(M=6.34)$, Defenders $(\mathrm{M}=5.86)$ and Goalkeepers $(\mathrm{M}=5.61)$, we did not find any significant differences in those variables. According to Anagnostakos et al. (2015), hematological variables such as RBC, HGB, HCT, iron concentration, and ferritin concentration determine aerobic capacity and skill improvement of football players. The objectives of the study were to test the effects of six-month training on hematological variables of soccer players. 25 professional football players were involved in the study and evaluated pre, during and postcompetition periods. Based on the results of the study researcher concludes that 6-month aerobic training helps develop hematological parameters of soccer players (Saddam et al., 2017). Conducted an analytical study on the effects of the preparatory training session on hematological parameters of Algerian soccer players. Twenty-three football players participated in the study with 14 weeks of training. The results of the study showed that there were significant differences in soccer player's results pre -post-test hematological variables. The study might serve as review literature of physiological researches.

\section{Conclusion}

These results of the study suggest that football players who play in different game positions did not have difference in WBC, RBC, HGB, HCT, $\mathrm{MCV}, \mathrm{MCH}, \mathrm{MCHC}$, PLT, LYM\%, NEUT\%, LYM\#, NEUT\#, RDW, PDW, MPV and PCT. The study included only the football players of Tigray region. Coaches and researchers in sport sciences take into consideration positional differences and training status of players during testing hematological profiles, as well as regional differences.

\section{Conflict of Interest}

The author declares that no conflict of interest in this research study.

\section{Acknowledgment}

We would like to thank Mekelle University for providing finance for conducting the study.

\section{References}

Anagnostakos, K., Eleftherios, M., Gissis, I., Gioldasis, A., \& Bekris, E. (2015). From Preparation to Competitive Period in Soccer: Hematological Changes. Sport Science Review, 24(1-2), 103-114

Anđelković, M., Baralić, I., Đorđević, B., Stevuljević, J. K., Radivojević, N., Dikić, N., Škodrić, S. R., \& Stojković, M. (2015). Hematological and biochemical parameters in elite soccer players during a 
competitive half season. Journal of Medical Biochemistry, 34(4), 460-466.

Boucherie, F., Millet, G. P., Hauser, A., Steiner, T., Wehrlin, J. P., Rysman, J., \& Girard, O. (2015). Association of hematological variables with teamsport specific fitness performance. PLoS ONE, 10(12), 1-12.

Bragazzi, N. L., Owen, A. L., Chtara, M., Cossio-Bolaños, M. A., Dunlop, G., Chamari, K., \& Rouissi, M. (2018). Stability in post-seasonal hematological profiles in response to high-competitive match-play loads within elite top-level European soccer players: implications from a pilot study. Open Access Journal of Sports Medicine, 9, 157-166.

Bussollaro, A.K., Freitas, B.N., Fadel, R.M., Lara, G.S., Barbosa, P.D., \& Mezzomo, T.R. (2018). Hematological parameters and body composition of soccer players. Rev Bras Med Esporte, 24(3), 202-205.

Cossio-Bolanos, M., Gómez-Campos, R., Andruske, C.L., Olivares, P.R., Santi-Maria, T., Lazari, E., Rocha, C.L., \& Arruda, M. (2015). Hemoglobin concentration and resilience of professional soccer players residing at sea level and moderate altitude regions. JEP Online, 18(1), 76-84.

Jastrzebski, Z., Radziminski, L., \& Stepien, P. (2016). Comparison of time-motion analysis and physiological responses during small-sided games in male and female soccer players. Baltic Journal of Health and Physical Activity, 8(1), 42-50.

Joksimović, A., Stanković, D., Ilić, D., Joksimović, I., \& Jerkan, M. (2009). Hematological profile of Serbian Youth National Soccer Teams. Journal of Human Kinetics, 22(1), 51-59.
Joksimović, A., Stanković, D., Ilić, D., Joksimović, I., \& Jerkin M. (2009). Hematological profile of Serbian youth national soccer teams. Journal of Human Kinetics, 22, 51-60.

Saddam, A., Ali, B., \& Abdelatif, H. (2017). Analysis of the evolution of some hematological parameters during the first preparatory period on young Algerian soccer players (U17). European Journal of Physical Education and Sport Science, 3(10), 128-134.

Santi Maria, T., Arruda, M., Portella, D., Vargas Vitoria, R., Gómez Campos, R.G., Martinez, C., Carrasco, V., \& Cossio-Bolanos, M. (2013). Hematological parameters of elite soccer players during the competitive period. JEP Online, 16(5), 68-76.

Shaskey, D.J., \& Green, G.A. (2000). Sports hematology. Sports Medicine, 29(1), 27-38.

Sporis, G., Jukic, I., Ostojic, S.M., \& Milanovic, D. (2009). Fitness profiling in soccer: physical and physiologic characteristics of elite players. J Strength Cond Res, 23(7), 1947-1953.

Sporis, G., Vlahović, T., Trajković, N., Milanović, Z., \& Madić, D. (2016). Hematological and iron status following a soccer match. FU Phys Ed Sport, 14(2), 289-295.

Stølen, T., Chamari, K., Castagna, C., \& Wisløff, U. (2005). Physiology of soccer: an update. Sports Med, 35(6), 501-536.

Younesian, A., Mohammadion, M., \& Rahnama, N. (2004). Hematology of professional soccer players before and after 90 min match. Cellular and Molecular Biology Letters, 9(2), 132-136. 